\title{
Making Asian Learners Talk: Encouraging Willingness to Communicate
}

\author{
Vatsana Vongsila \\ National University of Laos, Laos
}

\section{Hayo Reinders}

Unitec, New Zealand

\begin{abstract}
Developing English for communicative purposes is a key objective of language classes in many parts of the world. As a logical prerequisite to communication practice, learners need to have Willingness to Communicate (WTC) before they will engage in L2 interaction (Macintyre et al., 1998). Teachers can play an important role in helping learners to develop WTC (Dörnyei, 2007), however, since research into this topic is relatively recent, not much is known about how teachers go about this process. For this reason, the present study investigated teachers' perceptions of their role in fostering WTC through interviews and questionnaires and compared these with observations of their classroom practices. The research was conducted in $\mathrm{New}$ Zealand ESOL class that focused predominantly on communicative skills, catering mostly to Asian learners. The results showed that teachers believed they play a key role in helping learners to develop WTC and identified a range of strategies they used in class. Classroom observations confirmed the use of some strategies although no explicit encouragement of language practice outside the classroom was made. This paper identifies some possible reasons for this mismatch and concludes with practical recommendations for ESOL teachers who wish to support learners' WTC.
\end{abstract}

\section{Keywords}

Willingness to communicate, teachers' beliefs, interaction, teachers' perceptions, output

\section{Corresponding author:}

Hayo Reinders, Unitec Institute of Technology, Private Bag 92025, Victoria Street West,

Auckland I 142, New Zealand.

Email: info@innovationinteaching.org 


\section{Introduction}

A key goal of many English language programmes is to develop learners' productive language skills. Teachers naturally play a vital role in encouraging learners' Willingness to Communicate (WTC), which MacIntyre et al. (1998: 547) define as a 'readiness to enter into the discourse at a particular time with a specific person or persons, using a L2' and believe to be associated with factors such as learners' personality and motivation, as well as societal variables. Lockley (2013) argues that greater WTC can result in greater exposure to L2 input and, indirectly, to greater proficiency. However, Tong (2010) shows that many ESOL students keep quiet particularly during discussions and when teachers ask general questions. Several causes have been identified, including low speaking skills (Robertson and Nunn, 2007), high anxiety levels (Matsuda and Gobel, 2004: 23) and low self-confidence (Reinders and Wattana, 2013). The development of WTC is now increasingly seen as a measure of success for English language programmes (Mehrgan, 2013). In this article we look at teachers' beliefs and classroom practices in encouraging WTC in a language school in New Zealand that caters mainly to learners from Asia.

\section{Literature Review}

\section{Willingness to Communicate}

The use of L2 output (Gass and Mackey, 2015) and interaction (Long, 1996) are widely recognized as prerequisites for successful L2 acquisition. Neither is likely to occur without learners' desire to engage in language production. Fostering this Willingness to Communicate (WTC) is therefore now a fundamental goal of second language (L2) education worldwide (Riasati, 2012). According to MacIntyre et al., (2002: 539) 'willingness to communicate is the one, overwhelming communication personality construct which permeates every facet of an individual's life and contributes significantly to the social, educational, and organizational achievements of the individual'. Without WTC, students are less likely to engage in communicative activities and less likely to benefit from the advantages of L2 interaction such as increased input, negotiation of meaning, focus on form and so on.

\section{Factors Affecting WTC}

The extent of learners' WTC has been shown to vary depending on the situation they are in (Cao and Philp, 2006; Noels, 2001). Kang (2005) cited in Cao and Philp (2006: 481), believes that WTC 'may vary according to the interlocutor(s), topic, and conversational context, among other potential situational variables'. Anxiety and perceived competence (MacIntyre et al., 1999), communication confidence (Peng and Woodrow, 2010), classroom conditions, group cohesiveness and topic relevance (Aubrey, 2011) have all been identified as such situational variables.

Anxiety, in particular, appears to play a major role as it causes learners to avoid or reduce communication (Alemi et al., 2011; MacIntyre et al., 2002). MacIntyre et al. (2003) found that a majority of L2 students in a class they investigated attributed low participation to a lack of self-confidence but that increasing perceived speaking ability 
and lowering anxiety both fostered WTC. Interestingly, Matsuda and Gobel (2004) found that highly anxious people rate themselves lower in terms of speaking ability, so some of the variables affecting WTC appear to be interdependent. Similarly, Liu (2009) found that high levels of anxiety negatively affect performance and acquisition. However, Dörnyei (2005) suggests that students who speak less are anxious and then self-evaluated as less competent. Clearly, future research will have to untangle some of the directions of the effects of each of these variables.

\section{The Teacher's Role}

Previous studies have shown there are a number of tools at teachers' disposal to encourage WTC. Reducing group size appears to be an important factor, as it has been shown to reduce anxiety (De Léger and Storch, 2009); in particular groups of three or four participants can result in increased WTC, according to Cao and Philp (2006). Cao and Philp further proved that an increase in WTC was due to greater familiarity: with the interlocutor(s) and with the topics discussed. Kang (2005) too found that familiarity with other interlocutors influences WTC positively whereas new peers have the opposite effect; this is probably why many teachers experience classes taking some time to develop their own 'rhythm'. Similarly, Zhong (2013: 740), who investigated five Chinese immigrant learners' WTC in both teacher-led and collaborative learning situations in L2 classrooms, found pair work effective in developing communicative competence and increasing involvement. The extensive work of Philp et al., (2014) further illustrates the many benefits of peer interaction in second language learning.

Similar to Cao and Philp (2006), Kang (2005) and Riasati (2014) have shown that students feel less confident speaking on topics which they have little background knowledge in. In addition, Peng and Woodrow (2010) demonstrated that a general, pleasant classroom atmosphere can lead to less concerns with linguistic limitations. According to them, a positive classroom environment promotes involvement, diminishes anxiety and enhances self-confidence. Peng (2012) describes classroom atmosphere as inclusive of the emotions, mood, or climate sensed and shared by the group in class. As Riasati (2014) puts it, L2 students are simply more willing to speak in a student-friendly and supportive environment. Zhong (2013) contends that a relaxing environment increases learners' participation through mutual trust, an aspect that teachers have a degree of control over.

Another variable that impacts WTC, and one that is less under the direct control of the teacher, is self-perceived communication competence (MacIntyre, 1999), defined by Lockley (2013) as the ability to give or pass on information orally, and by Clément et al., (2003) as the belief that one can speak efficiently in a given situation. De Léger and Storch (2009: 269) showed that their learners' perceived oral ability affected their WTC so that 'as learners' self-confidence increased over time, so did their willingness to use the L2 in class'.

Finally, teachers' questions have been shown to play a role. Nazar and Allahyar (2012) found that open-ended questions asking for reason, explanation, description and opinion, lead students to reply with their own questions, asking for factual statements. A wait time of three seconds or more caused obvious changes in attitudes, expectations and language 
use. Groenke and Paulus (2007) demonstrate that teachers' questions can support a sustained discussion leading to multiple viewpoints. Classroom interaction patterns have been shown to have a significant influence on the type and frequency of student talk and as such is likely to have a major impact on WTC. Johnson (1997) reports on research into communication in second language classrooms, including what has become known as teacher talk. Estimates vary for the percentage of lesson time absorbed by the teacher's voice but the three functions of initiation, response and evaluation were long recognized as the pattern of teachers' classroom language internationally. More specifically, Farrell (2004: 60-61) reports the situation in Asian classrooms through a series of case studies. In answering the question 'How can teachers make classroom communication more effective?' Farrell refers to exploratory and final draft talk, the former happening when teachers seem 'to be rearranging their own thoughts as they speak', whereas the latter includes the evaluative phase.

Philp et al., (2014: 2) were interested in increasing student talk time through interaction with peers rather than with their teachers. The case for increasing the amount of such interaction time is supported by 'a steadily growing multidisciplinary body of research, from social, cognitive, and other perspectives'. During these periods students have both input and practice in such extra-classroom language functions as initiating topics, repairing misunderstandings, and using both open and closed questions. Philp et al., (2014) show that there is a focus on form and functions during peer interaction. In summary, certain interaction patterns appear to be conducive to L2 interaction and may also be beneficial to the development of WTC but more research is needed.

The overall picture then is of a complex interplay between variables that affect WTC, some of which are more directly under teachers' control than others. Although a number of such variables have been identified, it is unclear from the research how teachers' beliefs about (their role in encouraging) WTC relate to their classroom practice, and what interaction patterns characterize their classes. This is the focus of our research.

\section{Research Questions}

This study investigated ESOL teachers' beliefs about, perceptions of and practices in encouraging WTC inside and outside a New Zealand tertiary ESOL classroom.

The research questions are:

1. What are New Zealand ESOL teachers' beliefs about the importance of encouraging Willingness to Communicate?

2. What strategies do they use to encourage WTC?

3. What classroom L2 interaction patterns characterize their classes?

\section{Research Methods}

The study was carried out in the Language Department at Unitec Institute of Technology in New Zealand. This department, as many in New Zealand, caters largely to Asian learners and focuses heavily on the development of communicative language skills. Permission was obtained from the Head of the Department to conduct the research there, and ethics approval was obtained from the Unitec Research Ethics Committee. 
In order to answer our research questions, we used both quantitative and qualitative research methods; the quantitative to extract meaning from numerical data obtained from the questionnaire (see below) about teachers' beliefs and the strategies they employed, complemented with classroom observations and recordings.

First, all 30 teachers in the programme were sent an electronic questionnaire (appendix A) with 17 questions to establish their beliefs about the importance of encouraging WTC inside and outside the classroom. In the next section, ten strategies for encouraging WTC identified in the literature review above were provided and teachers were asked to identify which of these they used in class, and to give examples of how they did so. In addition, they had the option of listing other strategies they used, which were not on the list. In total, 15 responses were received (i.e. a response rate of 50\%). The results were analysed by calculating mean scores and percentages.

The first researcher observed each of the five participants' ESOL classes twice, for two hours each time. This was done using an observation sheet and an audio recorder. These five teachers were randomly selected from the pool of 15 questionnaire respondents. Through consultation with the teachers, those classes that were observed covered a wide range of language skills (e.g. classes focusing exclusively on writing practice were avoided). During the class, the observer sat at the back quietly and did not participate in the activities. Instead, she recorded:

1. Whether and how teachers used strategies for encouraging WTC.

2. Her own impression of the classroom atmosphere, noting such things as the presence or absence of laughter, whether students seemed relaxed or anxious, and so on.

3. The interaction patterns in class, noting, for example, who talked the most, the teacher or the students, the amount of peer talk, and so forth. Her notes, together with the audio recording were then analysed by:

a. Writing an impressionistic account of the class atmosphere.

b. Describing and counting the number of strategies used.

c. Recording the different types and frequency of interaction patterns.

\section{Results}

\section{Teachers' Beliefs about Their Roles in Encouraging WTC}

On a scale of 1-5, the questionnaire results (see the appendix for the questionnaire) show that teachers strongly agree that 'one of the most important roles for the teacher is to encourage students to speak in English in class' (4.46 out of 5), and only very slightly less so to 'encourage students to speak in English outside of class' (4.33 of 5).

\section{Strategies Used for Encouraging WTC in the Classroom}

Of the 10 strategies listed, teachers selected 8.4 on average; in other words, teachers said they used the majority of the strategies provided. Table 1 reports their responses from the 
Table I. Strategies Used by Teachers to Encourage WTC (Questionnaire Responses).

Group Size (14 Out of I5)

Fourteen teachers indicated actively adjusting group size to affect WTC. Teachers mostly use groups of three or four students, sometimes mixing levels and checking whether students preferred working with other students of their own nationality.

Cultural Backgrounds (I 4 Out of I5)

Fourteen teachers reported taking into account students' cultural backgrounds, by grouping and by topic choice. As one said, 'I try to organize students into familiar and unfamiliar groups works and have a cultural discussion'. Many also said they bring in topics relevant to the L2 learners' countries.

Self-perceived Speaking Ability (14 Out of I5)

Many teachers attempt to provide positive feedback by reinforcing student success, especially by commenting on students' voice recordings.

Class Atmosphere (13 Out of I5)

Many teachers attempt to build up a friendly and humorous class atmosphere through their choice of activities and through encouragement. Further, teachers ask numerous questions to create a productive classroom atmosphere and increase students' WTC.

Selection of Task Type (12 Out of 15)

Twelve respondents indicated they use specific tasks to improve students' WTC. For example, one respondent answered, 'I use small group talking activity or discussion'. Another teacher uses the conversation tasks to encourage interaction between students, and between teachers and students.

Reducing Shyness (13 Out of 15)

Thirteen teachers felt they could reduce students' shyness in such ways as by creating a friendly atmosphere within the classroom, by pairing students to get to know each other, by assigning students to small groups and to encourage them to engage in free conversation.

Self-confidence (13 Out of 15)

Most of the teachers used positive feedback, highlighting successes and providing encouragement.

Familiarity with the Interlocutor ( 13 Out of I5)

The teachers indicated that they actively try to create positive class dynamics in general and in particular to use activities that encourage students to talk to as many of their classmates as possible.

Reducing Anxiety (I 2 Out of I5)

Another popular strategy used by teachers is the reduction of anxiety. Most of the comments referred to letting students speak when they felt ready and not correcting mistakes. In addition, sharing humorous experiences was seen as a good way of lowering anxiety.

Topic Familiarity (8 Out of 15)

Only eight teachers mentioned increasing students' familiarity with topics used in class as a way of increasing WTC. Several use prior reading, while one suggested encouraging students to watch programmes such as the daily news. One teacher suggested students work online to search for information. 
most often to the least often mentioned strategies, and the ways in which the teachers indicated they implemented each strategy in class.

\section{Classroom Practice of Encouraging WTC}

In the next stage, five teachers' classes were observed twice, for two hours each time. The classroom observations showed the teachers used a range of techniques to encourage WTC, which could be grouped under three broad headings:

Warm-up Strategies: All five observed participants used warm-up strategies, albeit different ones. One asked students to share experiences of a tour in New Zealand. The class was animated, laughing and energized with almost all eager to speak. Another started by asking students what they had done during their weekend which led to active sharing of ideas as they smiled a lot and talked openly. In the class where students were asked to discuss a new item that they had found before class, they looked attentive and spoke freely for five minutes before the teacher asked for summaries. When one teacher suggested searching for a topic on the computer, students talked to each other informally. In the class that used images on the board to stimulate discussion, students appeared eager to supply responses and information.

Group Cohesiveness: All teachers applied group cohesiveness strategies to increase students' WTC, such as by asking students to work in groups and by giving them discussion tasks. Observations from all five classes showed that the learners worked together comfortably and exchanged ideas freely, with frequent laughter throughout the discussion.

Topic Choice: Almost all practicing teachers choose this 'right topic' strategy in order to raise their students' WTC. Two teachers asked students to present their own cultures to each other. Another participant initiated a current controversial topic, about the (then forthcoming) New Zealand general election.

\section{Classroom Interaction Patterns}

Analysis of the audio recordings of the classroom interaction patterns allowed us to identify the effect these had on the amount and type of student talk.

Talk Time: The audio recordings made in class gave us information about the amount of teacher and student talk. As can be seen in Figure 4.1, the five teachers spoke for an average of $63 \%$ during class time. The highest percentage was $85 \%$ and the lowest $42 \%$.

In addition to the division between teachers' and students' talk time, it is important to see how long each student speaks for. A large percentage of student talk time could be attributed to one student doing most of the talking, for example, or individual utterances could be frequent but very short. For this reason, Figure 4.2 illustrates the average length of each student's utterance. There is a considerable variation between the five classes, from a low of 6 seconds to a high of 11 .

Open-ended versus Closed Questions: Teachers asked a total of 148 open-ended (64\% of the total) and 85 closed questions (36\% of the total). The division is shown in Figure 4.3 for each teacher. 


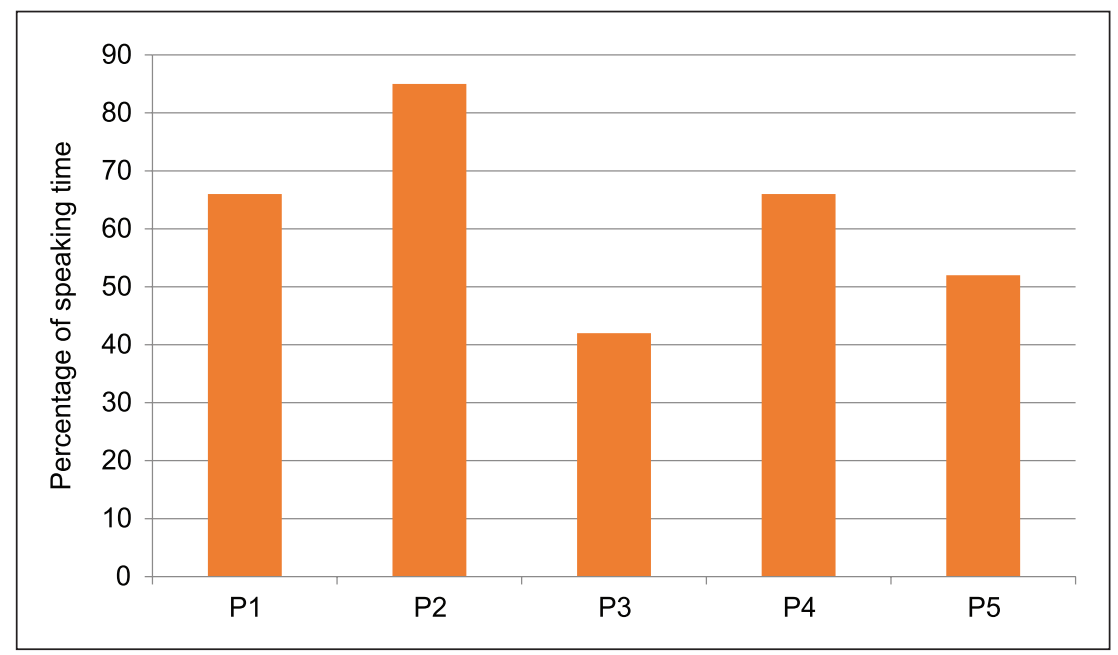

Figure 4.I. Percentage of Time Teachers Spoke in Class.

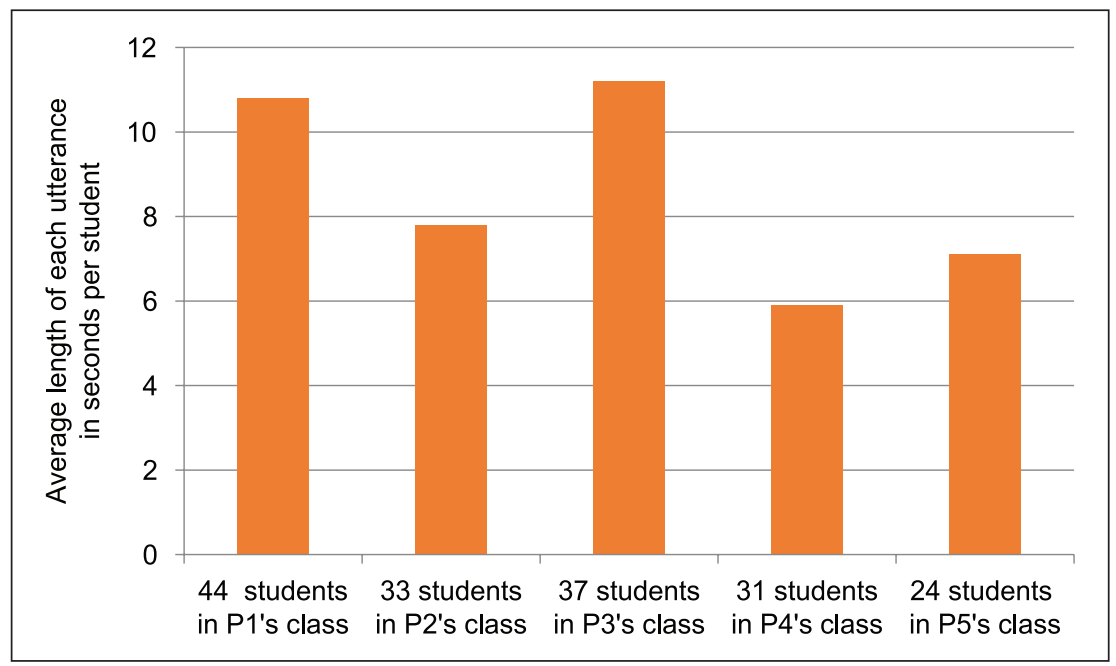

Figure 4.2. Average Length of Students' Utterances.

Response Length following Open-ended Questions and Closed Questions: Figure 4.4 shows that open-ended questions led to longer responses, with an average of 11.6 seconds, compared with an average of 2.2 seconds for closed questions. The total response time following closed questions of 123 seconds was only $28 \%$ of the 441 seconds of response time following open questions.

Wait Time: Average wait time after questions ranged from a low of 2 seconds to a high of 4.1 seconds, as shown in Figure 4.5. 


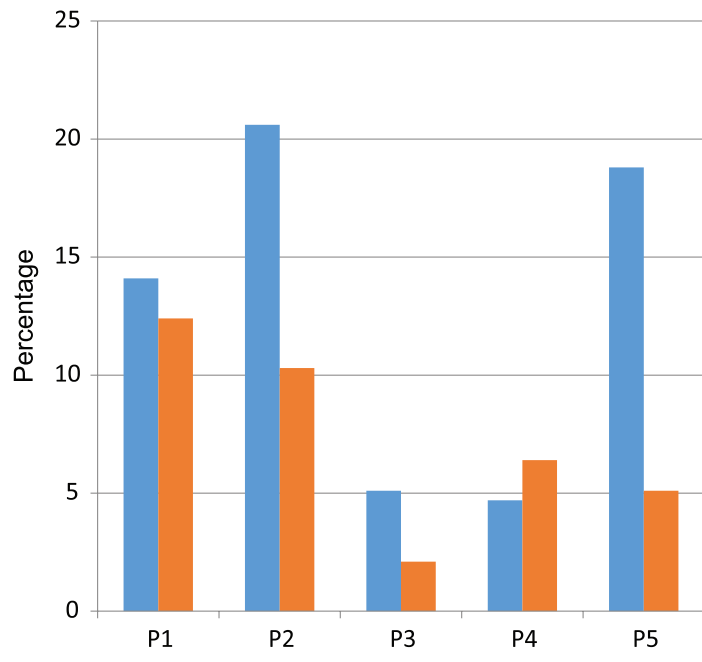

- Open-ended questions

- Closed questions

Figure 4.3. Percentage of Open-ended Questions and Closed Questions.

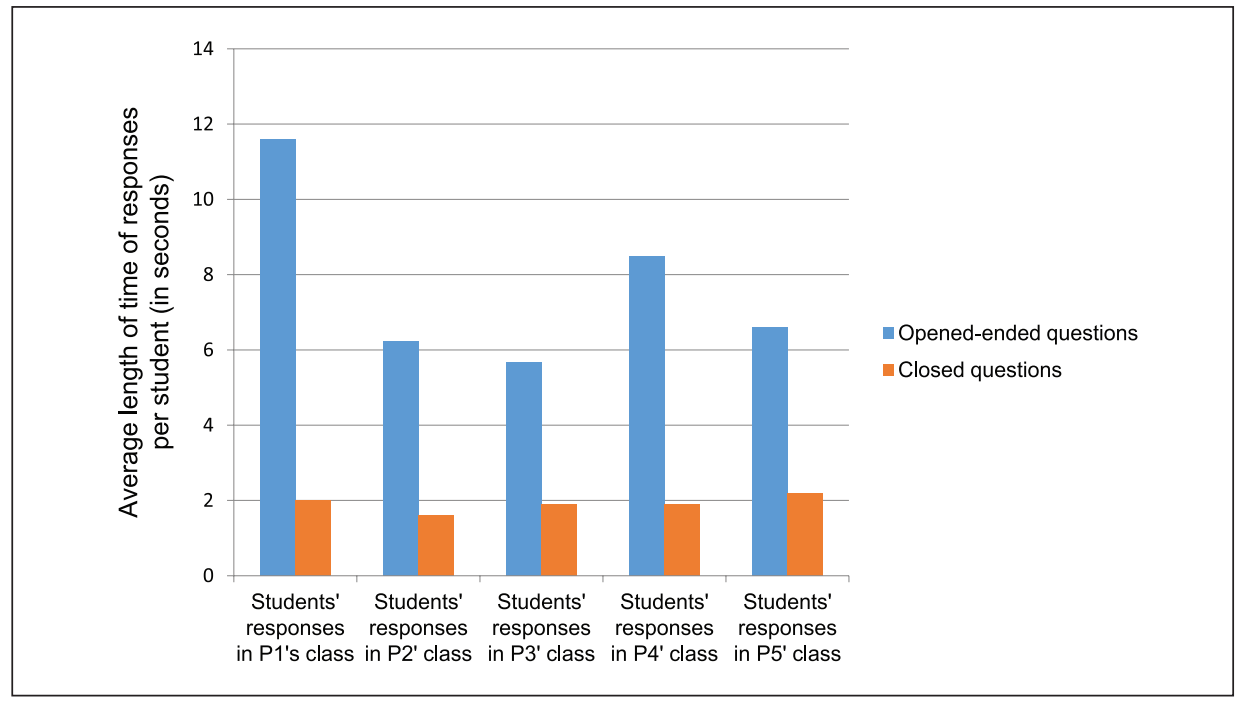

Figure 4.4. Comparison of the Length of Students' Responses to Open-ended and Closed Questions.

Students' Topic Initiation: To measure students' initiation of topics, we counted the number of times students asked for a change of topic. This happened three times in only one participant's class when they were asked to talk about 'politics' but requested instead to talk about fashion, music and entertainment. 


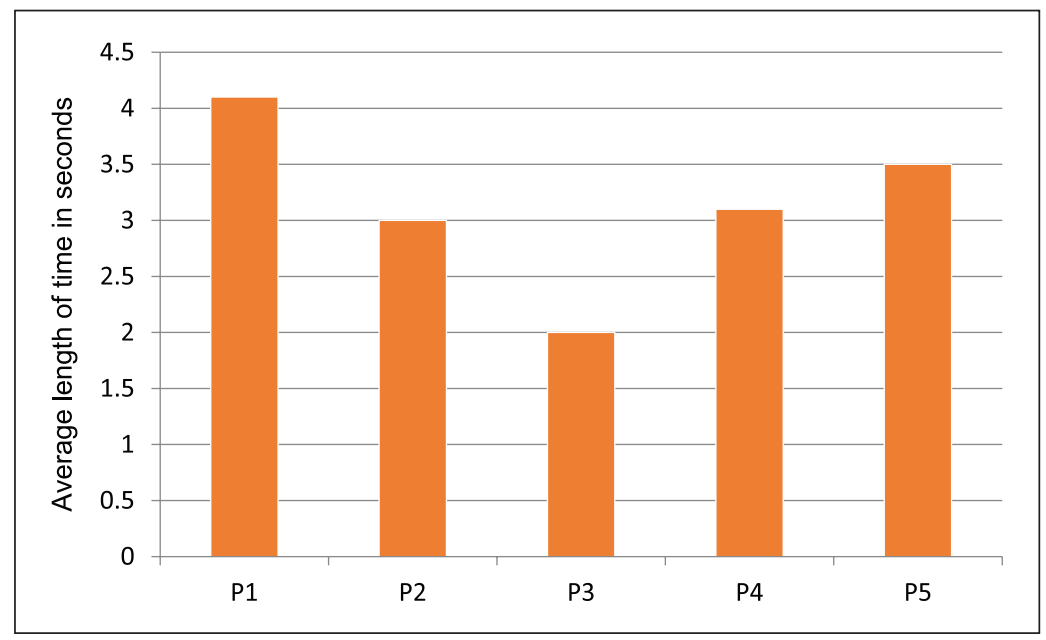

Figure 4.5. Average Wait Time.

Strategies Used for Encouraging WTC Outside the Classroom: An interesting finding from the observations was that the five teachers did not explicitly encourage or discuss communicating outside the classroom. They did not require students to apply new knowledge or to practise things learned in class in their own time, nor did they ask students to report if they had done so between classes. Students were not instructed in using strategies for communicating outside the classroom and were not given ideas or models on how to do so.

\section{Discussion}

In summary, the teachers in our study believe that encouraging WTC is their role. This is not surprising in the New Zealand context, where Communicative Language Teaching has been the norm for decades. Any of them who had qualified in the past 30 years or who had attended in-service courses during that time would have believed that talking and listening were essential elements in all English classrooms. Furthermore, their access to a range of teaching and learning resources would explain their confidence in carrying out this role. Here our findings echo those of Lee and $\mathrm{Ng}$ (2010) who found a similar conviction among English teachers of their role in encouraging learners to speak.

Perhaps as a result, teachers indicate using a wide range of strategies to encourage WTC. Many of these strategies have been observed in previous studies, such as adapting group sizes (Riasati, 2014), the use of group work (Ewald, 2004), building a rapport with the students (Matsuda and Gobel, 2004), and increasing students' familiarity with their interlocutors (Tsiplakides and Keramida, 2009). However our results show the full range of strategies teachers say they employ.

It is important to consider to what extent the teachers' attempts at encouraging WTC align with their learners' previous experiences and their expectations. It is interesting to 
note the very small number of times students initiated a topic in class. Although the overall atmosphere in the five observed classes seemed positive and relaxed, and although all 15 questionnaire respondents indicated they actively encouraged students to speak up, clearly most Asian learners did not do so, to the extent that they would suggest a change of topic. Although this is only one indication of students' WTC, it is an important one.

An interesting mismatch was found between teachers' perceptions and their classroom behaviour; although the questionnaire respondents overwhelmingly agreed that encouraging WTC outside the classroom is their responsibility, when the five ESOL classes were observed, no reference to communication outside of class was made. Such mismatches are not uncommon; for example Lee (2009) found that, although teachers believe feedback should cover both weaknesses and strengths, in practice they employed mostly error-correction in their feedback. Similarly, Zacharias (2005) found that teachers believed that they focused on speaking skills, when in actual fact their classes were focused more on other language areas. Nonetheless, considering our study took place in an ESL setting where opportunities for English use are abundant, this is a surprising finding.

In terms of classroom interaction, it was interesting to see the relationship between some of the teachers' behaviours and their impact on student talk. For example, openended questions led to longer responses (11.2 versus 2.2 seconds), and a reduced percentage of teacher talk was related to an increased percentage of student talk. Teacher 3 spoke the least amongst the five observed teachers and the amount of talk produced by the learners was the greatest. Of course, such variation can be due to other factors, but it is an interesting pattern nonetheless, which applied across the five classes. Previous research (Lewis and Reinders, 2003) has shown similar effects with teachers of Asian students, but also found a lower threshold of teacher talk beyond which learners ended up speaking less, probably as a result of needing some direction and guidance.

\section{Conclusions and Recommendations}

This study investigated the perceptions of ESOL teachers about WTC inside and outside New Zealand classrooms, finding that teachers do believe WTC is important, that they have a significant role to play in encouraging it, and that they employ a wide range of strategies to do so. The study also showed how some of the classroom L2 interaction patterns may relate to the teacher's behaviour. Interestingly, there was a mismatch between teachers' perceptions and their classroom practice; although they greatly valued the importance of encouraging WTC outside the classroom, we did not find any evidence of teachers doing so.

With regards to the ten variables identified from the literature that affect WTC, the respondents reported using a range of techniques to implement these in class. A key point was teachers' beliefs that they can overcome the variables influencing L2 WTC, such as using pair work and group work and helping learners control anxiety through encouragement. Indeed we found some evidence for their efficacy in the sense that these led to a 
relaxed and supportive atmosphere in each of the five classes observed, and considerable student talk.

Some practical implications arise from the study. Firstly, teachers clearly play a crucial role in persuading students to be more willing to communicate, a finding that echoes previous studies (Cao, 2009; Kang, 2005; Liu and Jackson, 2008; Liu, 2005; Matsuda and Gobel, 2004; Riasati, 2014; Tong, 2010). Secondly, there seems to be a relationship between the percentage of teacher talk and student talk and teachers may thus wish to monitor the amount they speak and how changes therein impact learner talk. Finally, it is important for teachers to be more mindful of encouraging students to use English outside the classroom with colleagues, friends, and family members, or online.

\section{Limitations of the Research}

Every research study has its limitations, and this project is no exception - one is the many variables that could have impacted the findings. For example, when observing the way teachers used warm-up strategies, it was evident that particular techniques resulted in more student engagement. However, this could have been the result of the relationships the teachers had already built with the students during previous classes. Nevertheless, the results provide a useful snapshot.

Another limitation is that the data was collected in only one language institution in one New Zealand city (Auckland), with 15 teachers participating in the questionnaire and five in the observations. Hence, results might not represent the perceptions of ESOL teachers nationwide. Similarly, we focused here on the teachers, not the students. A future study could compare teachers' perceptions of their efforts at encouraging WTC, how successful they feel they are at this, and students' selfreported WTC.

Future studies could pick up on the finding that the teachers in our study did not actively promote the use of English outside the classroom, particularly in an L2 environment. In addition, three WTC strategies adopted by this study's participants seem to be worth further exploration. A few teachers set the task of asking students to go online to search for information. The use of the Internet as a resource for language teachers and learners in a variety of ways is, in the view of this researcher, an important area for future study. Another technique was asking students to listen and imitate. Future research needs to investigate more specifically how the imitation factor improves students' speaking ability.

Finally, it would be particularly useful for future research to directly compare the types and number of WTC strategies teachers use and their impact on classroom interaction. Although we obtained some interesting results, by directly investigating the link between teacher behaviour and L2 interaction, more decisive conclusions may be drawn about the ways in which teachers can impact WTC.

\section{Acknowledgements}

We would like to thank Marilyn Lewis for her help with this article. 


\section{Funding}

This research received no specific grant from any funding agency in the public, commercial, or not-for-profit sectors.

\section{References}

Alemi M, Daftarifard P, and Pashmforoosh R (2011) The impact of language anxiety and language proficiency on WTC in EFL context. Cross-Cultural Communication 17(3): 150-66.

Aubrey S (2011) Facilitating interaction in East Asian EFL classrooms: increasing students' willingness to communicate. Language Education in Asia 2(2): 237-45.

Cao Y (2009) Willingness to communicate and communication quality in ESL classrooms. TESL Reporter 45(2): 18-36.

Cao Y, Philp J (2006) Interactional context and willingness to communicate: comparision of behavior in whole class, group and dyadic interaction. System 34(4): 480-93.

Clément R, Baker SC, and MacIntyre PD (2003) Willingness to communicate in a second language: the effects of contect, norms, and vitality. Journal of Language and Social Psychology 22(2): 190-209.

De Léger S, Storch N (2009) Learners' perceptions and attitudes: implications for willingness to communicate in an L2 classroom. System 37(2): 269-85.

Dörnyei Z (2005) The Psychology of the Language Learner: Individual Differences in Second Language Acquisition. London: Lawrence Erlbaum Associates.

Dörnyei Z (2007) Creating a motivating classroom environment. International Handbook of English Language Teaching 15(1): 719-31.

Ewald J (2004) A classroom forum on small group work: learners see and change themselves. Language Awareness 13(3): 163-79.

Gass SM, Mackey A (2015) Input, interaction and output in second language acquisition. In: VanPatten B, Williams J (eds) Theories in Second Language Acquisition: An Introduction. New York: Routledge, 180-206.

Groenke SL, Paulus T (2007) The role of teacher questioning in promoting dialogic literary inquiry in computer-mediated communication. Journal of Research on Technology in Education 40(2): 141-64.

Johnson E (1997) Cultural norms affect oral communication in the classroom. New Directions for Teaching and Learning 1997(70): 47-52.

Kang SJ (2005) Dynamic emergence of situational willingness to communicate in a second language. System 33(2): 277-92.

Lee I (2009) Ten mismatches between teachers' beliefs and written feedback practice. ELT Journal 63(1): 13-22.

Lee W, Ng S (2010) Reducing student reticence through teacher interaction strategy. ELT Journal 63(3): 302-313.

Liu MH (2005) Reticence in oral English language classrooms: a case study in China. TESL Reporter 38(1): 1-16.

Liu M (2009) Reticence and Anxiety in Oral English Lessons. Bern: Peter Lang.

Liu M, Jackson J (2008) An exploration of Chinese EFL learners' unwillingness to communicate and foreign language anxiety. The Modern Language Journal 92(1): 71-86.

Lockley T (2013) Exploring selfperceived communication competence in foreign language learning. Studies in Second Language Learning and Teaching 3(2): 187-212. 
MacIntyre PD, Baker SC, Clement R, and Donovan L (2002) Sex and age effects on willingness to communicate, anxiety, percieved competence, and L2 motivation among junior high school French immersion students. Language Learning 52(3): 537-64.

MacIntyre PD, Baker SC, Clement R, and Donovan L (2003) Talking in order to learn: willingness to communicate and intensive language programs. The Canadian Modern Language Review 59(4): 589-607.

MacIntyre PD, Babin PA, and Clément R (1999) Willingness to communicate: antecedents \& consequences. Communication Quarterly 47(2): 215-229.

Matsuda S, Gobel P (2004) Anxiety and predictors of performance in the foreign language classroom. System 32(1): 21-36.

Mehrgan K (2013) Willingness to communicate in second language acquisition: a case study from a socio-affective perspective. Journal of Comparative Literature and Culture 2(4): 172-75.

Nazar A, Allahyar N (2012) Increasing willingness to communicate among English as a foreign language (EFL) students: effective teaching strategies. Investigations in University Teaching and Learning 8(1): 18-29.

Noels KA (2001) New orientations in language learning motivation: toward a model of intrinsic, extrinsic, and integrative orientations and motivation. In: Dörnyei Z, Schmidt RW (eds) Motivation and Second Language Acquisition. Honolulu: University of Hawai'i, Second Language Teaching \& Curriculum Center, 43-68.

Peng JE (2012) Towards an ecological understanding of willingness to communicate in EFL classroom in China. System 40(2): 203-2013.

Peng JE, Woodrow L (2010) Willingness to communicate in English: a model in the Chinese EFL classroom context. Language Learning 60(4): 834-76.

Philp J, Adams R, and Iwashite N (2014) Peer Interaction and Second Language Learning. Oxford: Routledge.

Riasati MJ (2012) EFL learners' perception of factors influencing willingness to speak English in language classrooms: a qualitative study. World Applied Sciences Journal 17(10): 1287-97.

Riasati MJ (2014) Causes of reticence: engendering willingness to speak in language classrooms. International Journal of Research Studies in Language Learning 3(1): 115-22.

Robertson P, Nunn R (2007) The Study of Second Language Acquisition in the Asian Context. Seoul: Asian EFL Journal Press.

Tong J (2010) Some observations of students' reticent and participatory behaviour in Hong Kong English classrooms. Journal of Foreign Language Teaching 7(2): 239-54.

Tsiplakides I, Keramida A (2009) Helping students overcome foreign language speaking anxiety in the English classroom: theoretical issues and practical recommendations. International Education Studies 2(4): 39-44.

Zacharias NT (2005) Teachers' beliefs about internationally-published materials: a survey of tertiary English teachers in Indonesia. RELC Journal 36(1): 23-37.

Zhong QM (2013) Understanding Chinese learners' willingness to communicate in a New Zealand ESL classroom: a multiple case study drawing on the theory of planned behavior. System 41(3): 740-51.

\section{Appendix I - Questionnaire}

Topic: Teachers' and students' perceptions of Willingness to Communicate in an ESOL classroom.

The purpose of this questionnaire is to 1) identify the factors that affect students' willingness to communicate inside and outside the ESOL classroom, and 2) to explore 
what activities teachers employ in class to encourage willingness to communicate. Your answers will be anonymous.

1 Part I. Background Information 1. Please indicate your gender

$\square$ Male

$\square$ Female

2. Please indicate your experience in teaching English (including previous jobs)

$\square$ Less than 1 year

$\square 2$ - 5 years

$\square$ - 10 years

11- 15 years

$\square$ More than 15 years

3. What is your highest qualification in language teaching? (Please write your answer below).

2 Part II. Willingness to communicate (WTC) is usually defined as a speaker's willingness to speak in class and outside the class. If you do not think that this definition accurately describes willingness to communicate, please provide your own definition in the box below.

1. Please indicate how strongly you agree with this statement: 'One of the most important roles for the teacher is to encourage students to speak in English in class'.

$\square$ Strongly agree

$\square$ Agree

$\square$ Undecided

$\square$ Disagree

$\square$ Strongly disagree

2. Please indicate how strongly you agree with this statement: 'One of the most important roles for the teacher is to encourage students to speak in English outside the class'.

$\square$ Strongly agree

$\square$ Agree

$\square$ Undecided

$\square$ Disagree

$\square$ Strongly disagree

3. Each of the following variables has been shown to influence students' willingness to communicate. Which ones do you feel you actively impact through your teaching?

$\square$ Shyness 


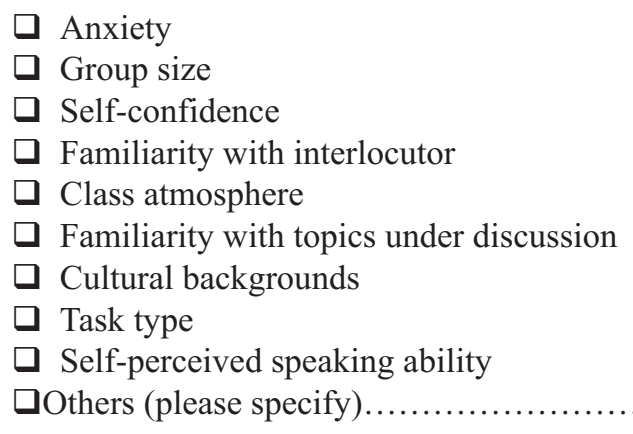

4. Think about the last class that you taught and answer the following questions: a. Shyness: What did you do to help students overcome their shyness?

b. Anxiety: What did you do to help students overcome their anxiety?

c. Group size: What did you do adjust group size to encourage students' WTC?

d. Self-confidence: What did you do to help students to improve their self-confidence?

e. Familiarity with interlocutor: What did you do to improve students' familiarity with their interlocutors?

f. Familiarity with topics under discussion: How did you improve students' familiarity with the topics under discussion? 
g. Cultural backgrounds: What did you do to take into account students' cultural backgrounds?

h. Task type: What specific task types did you use to improve students' WTC?

i. Class atmosphere: What did you do to improve the class atmosphere to encourage students' WTC?

j. Self-perceived speaking ability: How did you attempt to improve students' self-perceived speaking ability?

Thank you very much for helping us with our research. If you have any comments about this questionnaire, please type them in the box below. 